\title{
Intralesional Injection of 5-Fluorouracil in Verruca Vulgaris: Immunohistochemical and Clinical Study
}

\author{
A.A.El-Rifae ${ }^{1}$, H.A.Agina ${ }^{1}$, E.M.Akl ${ }^{2}$ and A.N.Dawod ${ }^{1}$ \\ ${ }^{1}$ Dermatology, Venereology and Andrology Dept., Faculty of Medicine, Benha Univ., Benha, Egypt \\ ${ }^{2}$ Pathology Dept., Faculty of Medicine, Benha Univ., Benha, Egypt \\ E-Mail: A.N.@gmail.com
}

\begin{abstract}
VV speak to a problematic remedial issue for the two patients and doctors. In this investigation, we planned to assess the clinical adequacy and wellbeing of intralesional 5-fu in the treatment of headstrong vv in grown-up patients. It included 60 patients. Subjects and techniques: The patients were isolated into 2 gathering, Group I: As a benchmark group of 10 solid volunteers were biopsied from typical non sun uncovered skin utilizing 4-6mm punch biopsies and Group II: 50 patients with vv exposed to: Group IIa: 15 vv were biopsied before infusion of 5-fu for histological and immunohistochemical examination.Group IIb: 15 vv were biopsied after infusion of 5 -fu after 3,4and 7days for histological and immunohistochemical assessment. Infusions were rehashed like clockwork, most extreme for six infusions. Results : caspase-3 was somewhat communicated in completely contemplated instances of typical skin. Caspase-3 was communicated in just $40 \%$ of vv which have been biopsied before 5-fu infusion however after infusion the exepression expanded to $86.7 \%$. The previously mentioned findings may reveal insight into the counter apoptotic physiologic part of caspase-3 in typical skin. Caspase-3 over articulation ater 5-fu infusion proposes a likely function of 5-fu on enlistment of apoptosisConclusion: 5-fu is a promising compelling and safe methodology for the treatment of different vv with high freedom rate, gentle and transient unfriendly impacts.
\end{abstract}

\section{Introduction}

Numerous ruinous and immunotherapeutic modalities have been utilized in the therapy of Verruca vulgaris (vv) damaging treatments incorporate either clinical agents,such as salicylic corrosive, trichloroacetic corrosive and 5-fluorouracil (5-FU), or careful techniques, for example, cryosurgery, careful extraction, electrocautry and laser removal. Immunotherapeutic specialists incorporate contact sensitizers, for example, dyphencyprone, immunomodulatory operators, for example, imiquimod, intralesional interferon and oral medications, for example, levamisole, cimetidine and zinc sulfate. Regardless of the presence of these various modalities, treatment of vv still speaks to a genuine test and an ideal treatment with widespread agreement is as yet anticipating [1].

5-FU is a fluorinated pyrimidine, which meddles with the blend of DNA and to lesser degree RNA, by restraining amalgamation of nucleic acids. 5-FU might be a viable treatment for vv, by meddling with the DNA and RNA amalgamation of both the infection particles just as the multiplying epidermal cells. 5-FU is utilized to treat various skin ailments in grown-ups including actinic keratosis, condyloma accuminata, and shallow basal cell carcinoma [2] .

5-FU has been utilized topically as an antiproliferative specialist for vv [3]. It has been recommended that 5-FU's capacity to repress DNA and RNA blend forestalls cell expansion and confines spread of the infection. The impacts of DNA and RNA hardship are generally articulated on HPVtainted cells, which develop all the more quickly and join 5-FU at an expanded rate when contrasted with solid tissue. Thus, 5-FU has a partiality for the quickly multiplying epidermis and virally tainted cells and effectsly affects the solid encompassing skin [4].

Apoptosis, otherwise called customized cell demise, assists with killing harmed cells and furthermore adds to the disposal of infection contaminated cells. The capacity of the host to trigger apoptosis in contaminated cells is maybe the most amazing asset by which infections can be cleared from the host life form. To dodge disposal by this component, human papillomaviruses (HPV) have created systems that empower the cells they contaminate to evade both extraneous and characteristic apoptosis [5].

Caspases are cysteine proteases that have basic functions in the organization of apoptosis, cutting objective proteins to execute cell passing. The cell dismantling characteristic for apoptosis is generally interceded by Caspase-3, which targets auxiliary substrates including atomic laminins, central bond locales and cell-cell adherence intersections [6].

Caspase-3 is the terminal killer protease in apoptosis, where it starts destroying of cell parts by means of cleavage of basic proteins, interruption of the atomic envelope, and breakdown of genomic DNA through enactment of caspase-initiated DNase [6].

The point of this examination is to assess the adequacy of intralesional infusion of $5-\mathrm{FU}$ in the treatment of VV, and to asses its impact on Caspase-3 articulation.

\section{Patient and method}

Prospective case control study was done in Dermatology \& Andrology and Pathology Departments in Benha University . 
This study included 60 participants complaining from multiple vv, were injected 5-fu, have been selected from Benha University Hospitals.

\section{All subjects will be subjected to the following:}

1- All patients were complaining of vv.

2- The size of $\mathrm{vv}$ was more than $0.5 \mathrm{~cm}$ in order to have good biopsies after injection of 5-fu.

3- All vv were not treated before by any other modalities as chemical caustics, cautary or surgical treatment. Such methods may change the histological picture of vv.

4- Full medical history taking from the patients .

5- Immunohistochemistry: Caspase 3 expression will be detected by immunohistochemistry.

6- Age more than 18 years old.

\section{Exclusion criteria for patients:}

1- Pregnancy, hepatits or, renal diseased patients and patients under chemotherapy.

2- Patients with Raynaud's phenomenon or vascular diseases.

3- Patients who have been treated from vv in the last 3 months.

4- Hypersensitivity to 5-fu.

5- Blood diseases.

6- Patients refused biopsy.

7- Connective tissue disease, rheumatoid artharitis.

\section{All patients were subjected to the following:}

- Type of vv, number, site, size, duration and course.

- They divided into 2 groups:

-Group I: As a control group of 10 healthy volunteers were biopsied from normal non sun exposed skin using 4-6mm punch biopsies.

- Group II: 50 patients with vv subjected t:

o Group IIa: 15 vv were biopsied before injection of 5-fu for histological and immunohistochemical examination.

- Group IIb: 15 vv were biopsied after injection of 5-fu after 3,4and 7days for histological and immunohistochemical examination.

$\circ 5-\mathrm{FU}$ is injected intralesionaly $\left(0.2 \mathrm{ml} / \mathrm{cm}^{2}\right.$ of 5 -fu , $50 \mathrm{mg} / \mathrm{ml}$ ) for $\mathrm{vv}$ up to $5 \mathrm{~mm}, 0.2$ to $0.5 \mathrm{ml}$ for $\mathrm{vv}$ up to $10 \mathrm{~mm}$ and larger $\mathrm{vv}$ received up to $1 \mathrm{ml}$ at the base of each vv till bleaching effect.

Injections were repeated every two weeks, maximum for six injections.

The biopsies were taken before 5-fu injection and after, 3, 4, 7 and 15 days of 5-fu injection. These biopsies were prepared for histological and immunohistochemical examination.

- Group IIc: the rest of vv were injected 5-fu and followed clinically up to 3 months for clearance of vv and recurrence.

Histological and immunohistochemical examination of group IIa and IIb.

For histopathological analysis ,sections of $4 \mu \mathrm{m}$ thickness were cut, dewaxed in xylene and then rehydrated in descending grades of alcohol and stained by conventional hematoxylin and eosin (H\& E) stain.

Detect the effect of intralesional injection of 5-fu into vv. The changes were graded as follows:

○ Grade 0: no changes as seen in classic histopathologic picture of vv.

- Grade 1: spongiosis, heamorrhage, basal edema and polymorphnuclear infiltrate in only one third of wart thickness.

○ Grade 2: the same changes in two thirds of vv thickness.

- Grade 3: the same changes in full thickness of the vv.

- $\quad$ For Immunohistochemical studies caspase-3 antibody was performed for all biopsies using Avidin Biotin complex technique:

- Immunohistochemically, caspase3expression was confirmed by cytoplasmic and/or nuclear stain in examined cells [7].

\section{Results}

Our outcomes shows that the age of the considered gathering went somewhere in the range of 20 and 45 years with mean of 31 years of age. The greater part of them were guys $(53.3 \%)$. Most of the examined females were housewives $(46.7 \%)$. Just a single forward of the gathering were smokers $(26.7 \%)$.

Our outcomes shows that the mean number of vv was 4 moles, their beginning was a half year and they were found to keep going for mean of almost 5 months. Hands were discovered to be the commonest influenced site followed by fingers $(33.3 \%$ and $20 \%$ individually). Most of the vv had a size of $0.5-1 \mathrm{~cm}$ $(80 \%)$ and $40 \%$ of them were of reformist course.

Our outcomes shows that all patients never get any treatment. Just $6.7 \%$ of patients experienced moles before and this patient had only one vv close by.

By overhauling family ancestry about vv, it was discovered that 4 patients had relatives experiencing vv. The commonest site of their vv was hand.

Half of them, their vv went on for one month and the subsequent half went on for a very long time.

Our outcomes shows that $80 \%$ of vv indicated decline in size after infusion of 5-FU. All patients experienced agony after infusion. The greater part of them encountered serious agony $(53.3 \%)$, while the staying $46.7 \%$ demonstrated moderate torment. Agony goal began during the second day in $73.3 \%$ of patients and during the third day in $26.7 \%$ of them. Patients got 3 to 6 infusions for treatment with mean of 4.6 infusions.

Our outcomes shows that $60 \%$ of patients demonstrated dark tone at the site of vv. The greater part of them encountered that change at the fourth day $(53.3 \%)$. Neither drain nor bullae arrangement was recognized. About $80 \%$ of patients were totally 
restored and most of them indicated that total fix following 2 months (28.6\%).

Our outcomes shows that there was non-critical distinction among when mediation as with respect to design, nonetheless, there was huge contrast between them as in regards to articulation, force and circulation.
Our outcomes shows that there were huge contrasts among when mediation as with respect to all $H \& E$ discoveries of mole biopsies like evaluation of spongiosis, discharge and basal edema.

Our outcomes shows that there was huge contrast among mediation and control bunches as with respect to design, articulation, force and appropriation.

Table (1) Comparison of immunohistochemistry finding of wart biopsies among the studied group.

\begin{tabular}{|c|c|c|c|c|}
\hline Variable & $\begin{array}{c}\text { Before } \\
\text { injection } \\
(n=15)\end{array}$ & $\begin{array}{c}\text { After } \\
\text { injection } \\
(n=15)\end{array}$ & Sign test & $P$ value \\
\hline \multicolumn{5}{|l|}{ Expression } \\
\hline Negative & $9(60)$ & $2(13.3)$ & $-2.646^{*}$ & 0.008 \\
\hline Positive & $6(40)$ & $13(86.7)$ & & $(\mathrm{S})$ \\
\hline \multicolumn{5}{|l|}{ Intensity } \\
\hline No & $9(60)$ & $2(13.3)$ & -2.271 & 0.02 \\
\hline Mild & $6(40)$ & $1(6.7)$ & & $(\mathrm{S})$ \\
\hline Moderate & $0(0)$ & $5(33.3)$ & & \\
\hline Strong & $0(0)$ & $7(46.7)$ & & \\
\hline \multicolumn{5}{|l|}{ Distribution } \\
\hline No & $9(60)$ & $2(13.3)$ & -2.236 & 0.02 \\
\hline Patchy & $6(40)$ & $7(46.7)$ & & $(\mathrm{S})$ \\
\hline Diffuse & $0(0)$ & $6(40)$ & & \\
\hline \multicolumn{5}{|l|}{ Pattern } \\
\hline No & $9(60)$ & $2(13.3)$ & -1.00 & 0.317 \\
\hline Nuclear & $3(20)$ & $7(46.7)$ & & $(\mathrm{NS})$ \\
\hline Nucleo-cytoplasmic & $3(20)$ & $6(40)$ & & \\
\hline
\end{tabular}

Table (2) Comparison of H\&E finding of wart biopsies among the studied group.

\begin{tabular}{|c|c|c|c|c|}
\hline Variable & $\begin{array}{c}\text { Before } \\
\text { injection } \\
(n=15)\end{array}$ & $\begin{array}{c}\text { After } \\
\text { injection } \\
(n=15)\end{array}$ & Sign test & $P$ value \\
\hline \multicolumn{5}{|c|}{ Grade of spongiosis } \\
\hline No change & $15(100)$ & $3(20)$ & -3.213 & 0.001 \\
\hline Mild change & $0(0)$ & $9(60)$ & & $(\mathrm{S})$ \\
\hline Moderate & $0(0)$ & $2(13.3)$ & & \\
\hline Severe & $0(0)$ & $1(6.7)$ & & \\
\hline \multicolumn{5}{|c|}{ Grade of hemorrhage } \\
\hline No change & $15(100)$ & $3(20)$ & -3.100 & 0.002 \\
\hline Mild change & $0(0)$ & $3(20)$ & & $(\mathrm{S})$ \\
\hline Moderate & $0(0)$ & $5(33.3)$ & & \\
\hline Severe & $0(0)$ & $4(26.7)$ & & \\
\hline \multicolumn{5}{|c|}{ Grade of basal edema } \\
\hline No change & $15(100)$ & $3(20)$ & -3.111 & 0.002 \\
\hline Mild change & $0(0)$ & $3(20)$ & & $(\mathrm{S})$ \\
\hline Moderate & $0(0)$ & $3(20)$ & & \\
\hline Severe & $0(0)$ & $6(40)$ & & \\
\hline
\end{tabular}

Table (3) Comparison of immunohistochemistry finding of vv biopsies among the studied groups.

\begin{tabular}{lllll}
\hline Variable & $\begin{array}{l}\text { Intervention group } \\
(\mathbf{n = 1 5})\end{array}$ & $\begin{array}{l}\text { Control } \\
\text { group } \\
(\mathbf{n}=\mathbf{1 0})\end{array}$ & Sign test & P value \\
\hline $\begin{array}{l}\text { Expression } \\
\text { Negative }\end{array}$ & $9(60)$ & $0(0)$ & 9.375 & 0.002 \\
Positive & $6(40)$ & $10(100)$ & & $(\mathrm{S})$ \\
\hline
\end{tabular}




\begin{tabular}{lllll}
\hline Table (3) Continue & & & & \\
\hline Intensity & $9(60)$ & $0(0)$ & 9.375 & 0.002 \\
No & $6(40)$ & $10(100)$ & & $(\mathrm{S})$ \\
Mild & $9(60)$ & & & \\
Distribution & $0(0)$ & $0(0)$ & 25.00 & $<0.001$ \\
No & $6(40)$ & $10(100)$ & & $(\mathrm{HS})$ \\
Patchy & & $0(0)$ & & \\
Diffuse & $9(60)$ & & 16.66 & 0.001 \\
Pattern & $0(20)$ & $0(0)$ & & $(\mathrm{S})$ \\
No & $3(20)$ & $4(40)$ & & \\
Cytoplasmic & $3(20)$ & $0(0)$ & & \\
Nuclear & & $60(60)$ & & \\
Nucleo-cytoplasmic & & & & \\
\hline
\end{tabular}

\section{Discussion}

In the present study,5-fu infusion was discovered to be compelling treatment in the treatment of verruca vulgaris . $80 \%$ of moles demonstrated reduction in size in the wake of getting 3to 6 infusions with mean of 4.6 infusions. About $80 \%$ of patients were totally restored and most of them demonstrated that total fix following 2 months.

The complete fix rate was distinctive in numerous preliminaries .It was $85 \%$ Artese et al., [8],75\% Kamal et al., [9], 60\% Kannambal et al., [10], 64.7\% Yazdanfar et al., (11), 84,8\% Zanini, D'Apparecida SMC, [13]. It was $95.38 \%$ Srivastava et al., [13].

The distinction noted in fix rate between various preliminaries might be because of various time stretch between measurements in various trials.5-FU was allowed like clockwork, greatest for six infusions by [9]. It was allowed at regular intervals, most extreme for 3 infusions by [10]. It was given week after week for four infusions by [11]. It was surrendered fortnightly for most extreme to two infusions by [13]. In this investigation, patients got 5fu at regular intervals with a greatest six infusions.

Another clarification for various fix rates might be identified with various portions of 5-fu in various preliminaries. In the investigation of [11], for instance, the portion of 5 -fu was $4 \mathrm{~mL}$ of $50 \mathrm{mg} / \mathrm{mL}$ 5-fluorouracil. In the investigation of [14], the portion of 5-fu was $2 \mathrm{ml}$. In the investigation of [9], the portion was $0.1 \mathrm{ml} / \mathrm{cm} 2$ of $5-F U, 50 \mathrm{mg} / \mathrm{ml}$.In the current examination 5-fu has been attempted in a portion of $0.2 \mathrm{ml}$ for moles up to $5 \mathrm{~mm}, 0.2$ to $0.5 \mathrm{ml}$ for moles up to $10 \mathrm{~mm}$ and bigger moles got up to 1 $\mathrm{ml}$.

The high achievement rate got in the current investigation might be identified with the generally apropriate portion applied, the shorter stretch among infusions, and the greatest number of meetings.

The remedial reaction was not influenced by age or sex of patients. The remedial reaction was not influenced by malady length or previous history of other treatment modalities.

In this examination, the event of restricted torment during and after 5-fu infusion was accounted for by essentially all patients. This agony was variable from moderate to serious. This torment was archived in practically everything preliminaries done on 5-fu $[9,10]$. In this examination, patients were encouraged to take ibuprofen to control this restricted torment. Torment goal began during the second day in $73.3 \%$ of patients and during the third day in $26.7 \%$ of them.

In this examination, $60 \%$ of patients indicated dark tone at the site of moles. The greater part of them encountered that change at the fourth day $(53.3 \%)$. Neither drain nor bullae arrangement was recognized.

$5-\mathrm{FU}$ is hence an extremely powerful and very much endured first line treatment in the treatment of VV paying little heed to patient's age, sex, sickness length or being treated before by any therapy methodology.

5-FU is a pyrimidine enemy, explicitly focusing on thymidylate synthetase and upsetting DNA amalgamation in mitotically dynamic cells It has been utilized topically in mole the executives. Nonetheless, inferable from helpless entrance effective 5-FU has not been exceptionally viable. Intralesional instillation of 5-FU, then again, takes into account restorative focuses to adequately arrive at the ailing site, consequently encouraging mole relapse [14].

In the current examination we have attempted to explain the potential components by which 5-fu produces its restorative impacts. Thirty patients (bunch IIaandgroup IIb) grumbled of vv (untreated previously) were exposed to intralesional 5-fu infusion then their moles were biopsied following 3 days. These biopsies were exposed to histopathological assessment by regular microscopy subsequent to recoloring by (HandE) stain.

After 5-fu infusion, practically all mole biopsies indicated histopathological changes as spongiosis, heamorrhage and basal edema. These progressions start to show up in moles following 2 days of infusion including just a single third of epidermal thickness. Following 3 days of 5-fu injection,these changes included practically all mole thickness.

The control of this gathering (bunch I from similar patients that didn't get intralesional 5-fu 
infusion. They were biopsied and analyzed after HandE stain. None of these moles gave any indication of spongiosis, heamorrhage or basal edema.

Apoptosis is an energy dependant modified cell demise that seems, by all accounts, to be the mode by which harmed cells are eliminated from the lesional tissue. Caspase- 3 is a chemical that assumes a key part in apoptosis; it is an individual from the group of cysteinyle aspartate explicit proteases. Caspase- 3 has been known as the killer caspase "cohort that goes around and executes the cell". CPP32, apoptin or YAMA are its different equivalents. Caspase-3 exists as an inert proenzyme which goes through proteolytic preparing and dimerizes to the dynamic compound structure [7].

Keratinocyte (KC) apoptosis assumes a basic function in directing epidermal turn of events and limiting carcinogenesis. Apoptosis adjusts multiplication to keep up epidermal thickness, adds to layer corneum development and may take out prethreatening cells. Aside from the typical formative program. While maladies related with expanded $\mathrm{KC}$ apoptosis will in general be intense, those related with diminished apoptosis will in general be constant. Truth be told, most skin ailments or cutaneous sores described by epidermal hyperplasia or hyperkeratosisas as vv likely include diminished $\mathrm{KC}$ apoptosis [15].

In the current investigation, caspase-3 was somewhat communicated with inconsistent conveyance in totally considered instances of ordinary skin. A little over half of the cases showed nucleo-cytoplasmic articulation in the lower $2 / 3$ of the epidermal layer while the rest showed cytoplasmic articulation.

Our outcomes are in concordance with Raymond et al., [16], who expressed that caspase-3 showed clear articulation in the epidermis which might be engaged with keratinocyte separation, and may incite apoptosis in light of uncovered cutaneous harm. These findings show that enactment of caspases doesn't really demonstrate that the cell is customized to pass on. Truth be told, a low degree of caspase enactment appears to assume an essential part in ordinary skin physiology. Non apoptotic part of caspase-3 has been as of late obvious [7].

In our current investigation, caspase-3 was communicated in just $40 \%$ of moles which have been biopsied before 5-fu infusion. The articulation was gentle and diffuse yet half of it was atomic and the other half was nucleo-cytoplasmic.

Then again, caspase-3 was communicated in $86.7 \%$ of moles which have been biopsied after 5 -fu infusion. The articulation was solid in $46.7 \%$ of positive cases,moderate in $33.3 \%$ and gentle in just $13.3 \%$ of positive cases. The articulation was inconsistent and atomic in $46.7 \%$ of positive cases yet diffuse and nucleo-cytoplasmic in $40 \%$.These discoveries indicated critical contrast among when mediation with respect to articulation, power and circulation.

\section{References}

[1] A .Nofal, E ,Nofal, Intralesional immunotherapy of common warts: successful treatment with mumps, measles and rubella vaccine. Journal of the European Academy of Dermatology and Venereology, Vol.24(10), PP.1166-1170,2010.

[2] C.Tracey, D.P.M. Vlahovic, R.C.P.S. Ffpm (Glasg), Current and Emerging Concepts in Wart Treatment, Indian J Sex Transm Dis AIDS. Jul-Dec, Vol.37(2), PP.210-212,2016.

[3] M.M. Lipke, An armamentarium of wart treatments. Clinical Medicine \& Research, Vol. 4(4), PP.273-293,2006.

[4] R.S.Salk, K.A. Grogan, T.J. Chang, Topical 5\% 5-fluorouracil cream in the treatment of plantar warts: a prospective, randomized, and controlled clinical study. J. Drugs Dermatol, Vol. 5, PP.418-424,2006.

[5] S.Shalini, L.Dorstyn, S.Dawar, "Old, new and emerging functions of caspases". Cell Death \& Differentiation, Vol. 22 (4), PP.526-539,2015.

[6] Galluzzi, Lorenzo, López-Soto, Alejandro, Kumar, Sharad, "Caspases Connect Cell-Death Signaling to Organismal Homeostasis". Immunity, Vol. 44(2), PP.221-231,2016.

[7] Bebars, Dalia Rifaat Al-Sharaky,corresponding author Mohammed A. Gaber, Dina Ragab Afify , Immunohistochemical Expression of Caspase-3 in Psoriasis: J Clin Diagn Res. Jul, Vol.11(7), PP.1$5,2017$.

[8] O. Artese, C .Cazzato, S .Cucchiarelli, (1994): Controlled study: medical therapy (5fluouracil, salicylic acid) vs physical therapy (DTC) of warts. Dermatol Clin, Vol. 14, PP.55$59,1994$.

[9] Tahir Kamal, Farhana, Ahmad, Usma Iftikhar Efficacy and safety of intralesional 5-fluorouracil in treatment of wartsJournal of Pakistan Association of Dermatologists, Vol. 28(3), PP.337-339,2018.

[10]K. Kannambal, P.K. Kaviarasan, P.V.S .Prasad, Efficacy of Intralesional 5- Fluorouracil in Recalcitrant Warts a study at Tertiary Care Centre. Journal of medical science and clinical research, Vol. 7(6), PP.556-560,2019.

[11]A. Yazdanfar , M. Farshchian , M. Fereydoonnejad Treatment of common warts with an intralesional mixture of 5-fluorouracil, lidocaine, and epinephrine: a prospective placebo-controlled, double-blind randomized trial. Dermatol Surg. May, Vol. 34(5), PP.6569,2008.

[12] M. Zanini , S.M.C.D’Apparecida Intralesional 5Fluorouracil: A New Approach for Recalcitrant and Periungual Warts. Med Cutan Iber Lat Am, Vol. 32 (5), PP.201-204,2004.

[13] B.C. Anukriti Srivastava1, Ghiya, Prasoon soni, 
204 Intralesional Injection of 5-Fluorouracil in Verruca Vulgaris: Immunohistochemical and Clinical Study

Efficacy of Intralesional 5-Fluorouracil in Treatment of Palmo-Plantar Warts. Int J Med Res Prof, Vol.2(3), PP.60-63,2016.

[14] A.K.Bubna , Successful management of recalcitrant perianal warts with two sessions of intralesional 5-fluorouracil. Indian J Sex Transm Dis [serial online] [cited 2020 Aug 28], Vol.37, PP.210-2,2016.

[15] Deepak Raj, E. Douglas Brash, Douglas
Grossman, "Keratinocyte apoptosis in epidermal development and disease." The Journal of investigative dermatology, Vol. 126(2), PP.243$57,2006$.

[16] A.A. Raymond, M.C. Mechin, R. Nachat, Nine procaspases are expressed in normal human epidermis, but only caspase-14 is fully processed Br J Dermatol, Vol. 156, pp. 420-427,2007. 